\title{
REPENSANDO A GESTÃO E A ORGANIZAÇÃO DO TRABALHO: PERSPECTIVAS DE INTERVENÇÃO A PARTIR DA PARTICIPAÇÃO DOS TRABALHADORES
}

\section{RETHINKING MANAGEMENT AND THE ORGANIZATION OF WORK: PERSPECTIVES OF INTERVENTION FROM THE PARTICIPATION OF WORKERS}

\author{
A.M.M .PIMENTA, E.C. FAGUNDES e J.N.G. ARAÚJO. ${ }^{1}$ \\ ${ }^{1}$ Pontifícia Universidade Católica de Minas Gerais - Programa de Pós-Graduação em Psicologia, Brasil.
}

ART ICLE INFO

Article history:

Received 2018-07-20

Accepted 2018-10-15

Available online 2018-10-31
Palavras-chave: Trabalho. Gestão. Saúde e adoecimento no trabalho. Clínicas do trabalho.

Keywords: Work. Management. Health and sickness at work. Work Clinics

*Autor correspondente:

E-mail:

amandamarquespimenta@yahoo.com.br.

RESUMO. O presente artigo apresenta o relato de duas experiências de pesquisa, realizadas com base na premissa de escuta e participação dos trabalhadores, a partir das clínicas do trabalho. A primeira pesquisa analisou a questão do reconhecimento dos empregados em uma empresa pública do setor de serviços; já a segunda permitiu discutir o trabalho dos agentes comunitários de saúde nas estratégias de matriciamento em saúde mental do SUS Betim. Ambas as experiências podem ser caracterizadas como pesquisa-ação, sendo que a primeira teve como referencial teórico a psicossociologia e a segunda a clínica da atividade. A análise das duas pesquisas em paralelo permitiu verificar que, mesmo se tratando de contextos muito distintos, a gestão das duas instituições é marcada pela submissão e ausência de escuta dos trabalhadores, o que causa sofrimento no trabalho. Por outro lado, a realização das duas pesquisas permitiu aos sujeitos se apropriarem de suas atividades laborais e passarem a sugerir mudanças, capazes de promover a saúde, a satisfação e o reconhecimento pela via do trabalho. $O$ artigo contribuiu para uma reflexão crítica acerca dos modos de gestão atuais, bem como apontou a para possibilidade de construção de uma nova gestão que traga melhorias tanto para os trabalhadores quanto para as organizações.

\footnotetext{
ABSTRACT. This article presents the report of two research experiences, based on the premise of listening and worker participation, from the work clinics. The first research analyzed the issue of employee recognition in a public sector service company; the second one allowed us to discuss the work of community health agents in SUS Betim mental health training strategies. Both experiences can be characterized as action research, the first one having as theoretical reference the psychosociology and the second the clinical of the activity. The analysis of the two parallel researches allowed to verify that, even in very different contexts, the management of the two institutions is marked by the submission and absence of listening to the workers, which causes suffering at work. On the other hand, the two researches allowed the subjects to appropriate their work activities and to suggest changes, capable of promoting health, satisfaction and recognition through work. The article contributed to a critical reflection on the current modes of management, as well as pointed to the possibility of building a new management that brings improvements both for workers and for organizations.
} 


\section{Introdução}

No modelo atual de capitalismo financeiro, observamos que tanto as empresas privadas quanto as instituições da administração pública adotam uma forma de gestão que zela, acima de tudo, pelos resultados financeiros, maximizados independentemente das consequências sofridas pelos trabalhadores, ou mesmo pelas próprias instituições, seus serviços e produtos (BOLTANSKI; CHIAPELLO, 2009).

Apesar do discurso frequente de que a gestão se encontra em evolução, considerando o trabalhador como o seu principal ativo, humano e intelectual, o que se observa na prática é um incremento dos modos de controle e exploração, que há muito deixaram de se ater apenas ao domínio dos corpos, mas voltaram seus olhares para as mentes daqueles que trabalham. De acordo com Siqueira (2010,165-166), "a gestão pressiona cada vez mais o indivíduo, assimilando a sua subjetividade, de modo a torná-lo servo de todo o processo produtivo que o coisifica e que impede, não raras vezes, a mobilização de sua criatividade profissional".

Segundo Pagès e outros (1993), o que se verifica nas organizações hipermodernas é que que suas estratégias de exploração e dominação podem se dissimular sob as vantagens e benefícios que elas fornecem aos indivíduos, levando-os mesmo a colaborar com a própria submissão.

Nesse contexto, o exercício do poder mostra-se bastante eficaz, na medida em que, apesar do constante incremento da exploração e do aumento dos casos de adoecimento laboral e precarização das condições de trabalho, nota-se um enfraquecimento dos mecanismos de defesa dos trabalhadores, sobretudo no âmbito coletivo, o que pode ser corroborado pelo esmaecimento dos coletivos de trabalho e da organização sindical, além da constante ameaça de desemprego.

Diante desse cenário, o papel da psicologia nas organizações vem sendo discutido e atravessado por perspectivas que buscam dar voz à experiência e ao conhecimento dos trabalhadores, assumindo uma postura crítica e clínica de transformação das situações de trabalho.

O presente trabalho tem como objetivo discutir alternativas para a gestão que possam ir de encontro a essa perspectiva hegemônica por meio de práticas que viabilizem o aumento da participação dos trabalhadores, a construção de formas de resistência e uma apropriação do trabalho por aqueles que realmente o fazem. Busca-se compreender e subsidiar a reflexão crítica dos sujeitos na situação de trabalho, questionando a organização como um todo, em virtude da preservação e da promoção da saúde. Ao longo do texto, são relatadas duas experiências de pesquisa, embasadas nessas premissas, discutindo-se as possibilidades de aplicação de uma gestão que promova a autonomia e valorize o saber daqueles que trabalham.

Tais propostas estão em consonância com o apontamento das clínicas do trabalho sobre a necessidade da construção de uma gestão mais humana dos recursos (GAULEJAC, 2007), a partir da premissa de que "as organizações funcionam porque os indivíduos em situação concreta 
de trabalho mobilizam sua inteligência prática para fazer as coisas acontecerem a despeito das regras e dos procedimentos prescritos frequentemente inaplicáveis" (CHANLAT, 2011, p. 117).

A presente reflexão possibilita deslocar o trabalho do reducionismo imposto pelo sistema atual para analisá-lo em uma perspectiva de desenvolvimento social, não restringindo o trabalho à sua institucionalização econômica, ou seja, o emprego (BENDASSOLLI; SOBOLL, 2011). Nesse sentido,

\begin{abstract}
Trabalhar não é apenas dedicar-se a uma atividade. É também estabelecer relações com os outros, envolver-se em formas de cooperação e de troca, inscrever-se numa divisão dos postos e das tarefas, confrontar os pontos de vista e as práticas, experimentar e dar visibilidade às capacidades e aos recursos de cada um, transmitir saberes e capacidades, validar as contribuições singulares... É, enfim, ser capaz de pôr a sua marca no seu ambiente e no curso das coisas. (LHUILIER, 2005, p. 217).
\end{abstract}

\title{
O olhar dos trabalhadores acerca do reconhecimento e de suas possibilidades na gestão atual
}

O presente relato consiste em uma pesquisa, concluída no ano de 2014 , acerca relação entre os sujeitos trabalhadores e o modelo de gestão de pessoas aplicado em uma empresa pública que atua no setor de serviços.

No desenvolvimento do trabalho, foram realizadas entrevistas individuais e coletivas com empregados de carreira técnica e gerencial. A referência teórica para a realização dessas entrevistas foi a psicossociologia, que tem como objeto de estudo o foi a psicossociologia, cujo objeto clássico de estudos é o sujeito social, em sua inserção nos grupos, organizações e instituições. Dentro desse contexto, o pesquisador aparece no papel de pesquisador-interventor, estruturando-se uma relação de colaboração com os operadores do trabalho, voltada para a transformação dos grupos em questão. O fato de se estruturar um diálogo com os trabalhadores mostra-se importante, quando é pensada a possibilidade de melhoria e aprimoramento dos efeitos que a relação entre a gestão de pessoas, os sujeitos e o trabalho pode produzir nos empregados e nas organizações.

Os relatos dos trabalhadores foram analisados a partir da técnica de análise de conteúdo, a qual, segundo Desprairies e Lévy (2005), tem como objetivo tornar os discursos mais inteligíveis e, portanto, mais acessíveis a muitas pessoas. Nesse sentido, há a passagem de um discurso singular, apropriado a uma utilização privada, para um discurso geral, inteligível para outros e que pode servir para fins coletivos.

Dentre as categorias de análise estabelecidas, foi definida a categoria "o reconhecimento dos sujeitos trabalhadores no contexto da gestão de pessoas", a qual foi analisada no presente artigo, não apenas como uma forma de diagnóstico, mas também como uma possibilidade de repensar a gestão a partir de uma perspectiva de participação dos trabalhadores.

Amado e Enriquez (2011) afirmam que, a partir da ideia de que cada sujeito procura 
reconhecimento por meio de seu trabalho nas organizações, sendo a vida humana uma luta pelo reconhecimento, esse processo pressupõe uma mediação. Aquela que se estabelece por meio do trabalho, crucial em Hegel (1992), permitiu aos psicossociólogos admitir essa importância, sem considerar, contudo, que ela seja a única possível. A mediação instaurada em qualquer grupo investido de uma significação central para os sujeitos parece ter uma força particular, tornando-se vital.

Por meio do trabalho, segundo Hegel (1992), em sua obra "Fenomenologia do espírito", a consciência encontra-se a si mesma através do outro e, numa trama dialética, mediada pelo trabalho. Este se apresenta como desejo refreado, desejo que não se satisfaz no imediato.

O desejo se reservou o puro negar do objeto e por isso só sentimento-de-si-mesmo, sem mescla. Mas essa satisfação é pelo mesmo motivo, apenas um evanescente, já que lhe falta o lado objetivo ou o subsistir. O trabalho, ao contrário, é desejo refreado, um desvanecer contido, ou seja, o trabalho forma. (HEGEL, 1992, p.132)

A análise dessa passagem permite compreender, conforme apontado por Araújo (2010), que o sentido do trabalho, para Hegel, envolve uma ação transformadora do mundo e, por consequência, do próprio sujeito. Ao transformar o objeto, o sujeito também se transforma ou se forma. Ele não é constantemente idêntico a si mesmo, tendo em vista que se constitui no curso de sua própria história. Diante disso, é possível estabelecer a primeira relação entre trabalho, temporalidade e subjetividade. Além disso, cabe ressaltar que a satisfação não é imediata na dimensão da consciência, uma vez que o desejo só se satisfaz por meio do trabalho que transforma o objeto. Essa impossibilidade de satisfação no imediato explica a presença da negatividade, relacionada ao trabalho, que surge, então, como um desejo refreado.

Hegel também discute o papel do outro, na relação entre desejo, trabalho e reconhecimento, conforme as passagens: "A consciência-de-si é em si e para si quando e porque é em si e para si para uma Outra; quer dizer, só é como algo reconhecido" (HEGEL, 1992, p. 126). O autor acrescenta:

Consideremos agora este puro conceito do reconhecimento, a duplicação da consciência-de-si em sua unidade, tal como seu processo se manifesta para a consciência-de-si. Esse processo vai apresentar primeiro o lado da desigualdade de ambas [as consciências-de-si] ou o extravasar-se do meio termo nos extremos, os quais, como extremos, são opostos um ao outro; um extremo é só o que é reconhecido; o outro, só o que reconhece. (HEGEL, 1992, p. 127-128).

A partir da discussão dessa relação, vemos que o reconhecimento é um elemento central na dialética hegeliana. A consciência-de-si quer dirigir-se ao mesmo tempo ao objeto exterior e a si mesma, fazer-se "em si" e "para si". Toma-se assim como objeto que pode se olhar. No entanto, esse olhar-se não se faz diretamente, mas através de outro olhar. Dentro desse movimento, ao transformar a coisa, o homem não o faz só para torná-la seu objeto, mas também para se fazer reconhecer por um outro homem, em seu desejo sobre a coisa e sobre esse outro. Configura-se, assim, a luta pelo reconhecimento. 
Hegel (1992) lançou as bases da sociabilidade e da intersubjetividade, ao propor o tema do reconhecimento. Para ele a "consciência-de-si" (hoje falaríamos de sujeito) só tem acesso a si mesma através da interiorização do olhar do outro. E foi por meio de sua "dialética do senhor e do escravo" que o tema do trabalho adquiriu um lugar central na trama do reconhecimento. No mundo das organizações, a problemática do reconhecimento costuma ser deturpada, quando se pratica uma valorização artificial e instrumental do trabalhador, na tentativa de seduzi-lo ou "motivá-lo", sem a contrapartida das retribuições prometidas, o que pode ser fonte de frustração, sofrimento ou mesmo adoecimento no trabalho.

Tendo como pressuposto que o reconhecimento consiste em um olhar e uma validação do outro, que pode ser a própria organização ou as demais pessoas que participam do trabalho, o relato dos empregados de carreira técnica da organização em estudo mostra que esse reconhecimento não acontece, uma vez que sua contribuição não está formalizada, seu papel não tem uma nomeação na estrutura organizacional.

Então, você tem que dar resultados, de acordo com as diretrizes que foram estabelecidas, e não pedir nada por isso. É claro que a gente vem sendo reconhecido na avaliação de desempenho, a gente tem notas muito boas, não seria diferente disso. Mas a dificuldade que a empresa tem pra reconhecer essa pessoa, esse talento, que assumiu as responsabilidades, aderiu isso espontaneamente. Porque quando você coordena, fala assim: "olha, você vai coordenar oito pessoas, você vai ser um avaliador dessas pessoas, você vai avaliar uma pessoa que tem uma equipe de nove, dez, até quinze pessoas abaixo dela, ela é reconhecida formalmente na empresa, mas você não vai aparecer em nada, em documento nenhum, porque a empresa não reconhece a sua coordenação. Então, você é um sujeito oculto. Claro, você tem lá... o gerente reconhece, o superintendente, o processo te reconhece, você fica visível lá, mas formalmente oculto (Participante do grupo de empregados de carreira técnica).

Segundo Lhuilier (2005), o reconhecimento pressupõe uma relação simbólica, na medida em que na medida em que o pertencimento a um grupo é que dá condições de suporte e aprovação social das próprias práticas. Estabelece-se um duplo reconhecimento, ao mesmo tempo social e pessoal. Do ponto de vista institucional, o reconhecimento pressupõe também salário e promoções, que são suportes necessários a um sujeito que tem necessidades simbólicas, psicológicas e materiais. No entanto, o reconhecimento não pode se restringir a esse aspecto. Essa falta do reconhecimento percebida tanto na fala dos gerentes quanto na dos empregados de carreira técnica tem como consequência uma diminuição do investimento dos trabalhadores na organização, o que aparece na fala como falta de motivação.

Falta de um reconhecimento de repente até individual, do dia a dia, de alguma coisa menorzinha, que não esteja vinculada com dinheiro. (gerente)

E aí você vai jogando as pessoas pra baixo e a motivação é diretamente proporcional ao desempenho. Quem está motivado entrega o mínimo e olhe lá. Quem está motivado, quer fazer mais, quer descobrir novas formas, se interessa pela coisa, e também se preocupa. $E$ você vai diminuindo essa média das pessoas que estão motivadas, com isso, porque você não tem retorno pelo que você faz de diferente. Quando você é diferencial, você não percebe um diferencial na política da empresa (participante do grupo de empregados de carreira técnica). 
Essa diminuição do investimento pode ser analisada a partir da perspectiva, apontada por Lhuilier (2005), de que a avaliação de um trabalho está vinculada aos olhares dos outros. É somente a partir do reconhecimento de um terceiro que eu vou me assegurar do valor, da utilidade ou da beleza daquilo que eu realizo.

. Esse processo é realizado a partir de diversos olhares que são marcados por necessidades e expectativas distintas, sendo todos fundamentais para o reconhecimento dos compromissos a satisfazer entre as diferentes exigências, encontrando um lugar e um modo próprio de realização.

Dentro desse contexto, a falta de motivação ou a vontade de fazer apenas o mínimo surgem como efeito da falta de retorno acerca do trabalho realizado.

Com relação aos gerentes, as falas, na maior parte das vezes, vinculam reconhecimento apenas à recompensa financeira. A partir disso, a ausência desse aspecto passa a ser justificada pelo fato de não haver dinheiro suficiente para concessão de aumentos salariais ou promoções.

[...] na medida de um possível que é um possível cada vez menor, há um reconhecimento através desse tal processo que eu te falei, da avaliação de desempenho, em que há uma distribuição de dinheiro anual, mas é pouco... é pouco (gerente).

Por outro lado, o discurso dos empregados de carreira técnica vem marcado por uma demanda por um reconhecimento que não é financeiro, mas que está vinculado à fala, a uma validação do outro.

Olha, muito bom o seu trabalho. Se você continuar assim você vai ser premiado. Você vai ter um prêmio pra isso". Um mérito, que é a questão da meritocracia, que felizmente ela aparece nos mapas hoje, depois de longos anos. Ela não existia nessa palavra, ela não era escrita no mapa, e ela tem no mapa, mas ela não se torna uma realidade na empresa. Você não dá crédito a quem merece. A meritocracia, na verdade, ela não existe (Resposta do grupo de empregados de carreira técnica).

É importante ressaltar que os empregados cobram a meritocracia, que pressupõe que cada sujeito tem habilidades, conhecimentos e competências distintas, que fazem com que eles estejam capacitados para atuações distintas. Tal concepção pressupõe a validação da contribuição individual e a possibilidade de escolha dentro do contexto profissional, o que é considerado reconhecimento e encontra-se em acordo com as considerações de Hegel acerca do olhar do outro. No entanto, os relatos dos empregados são marcados pela impossibilidade desse movimento.

Eu já vi pessoas que são boas de serviço, estão em desvio de função, estão lá fazendo seu serviço direitinho, fazendo seu dever de casa, contribuindo com muito mais, porque já está formado e está colocando conhecimento em cima daquilo ali e desenvolvendo um trabalho legal. Essa pessoa não consegue sair pra encarreirar em outra área. Ela é punida porque ela é boa de serviço. Em contrapartida, os "xiita", que é o nome que eles dão pros empregados rebeldes, que brigam, os "xiita", eles são tratados dessa forma, assim na palma da mão, e eu ouvi os gerentes 
oferecendo: "escolhe pra onde você quer ir que eu vou te liberar... (Participante do grupo de empregados de carreira técnica)

O contexto de prevalência da associação do reconhecimento apenas à recompensa financeira parece ser uma consequência direta da ideologia do modelo de gestão implantado, que se encontra focado apenas no resultado financeiro, sem olhar para o sujeito trabalhador ou para o trabalho em si. Tal constatação pode ser corroborada pela fala dos empregados de carreira técnica, para quem as oportunidades de conversa são mais marcadas por tentativas de justificar a falta de aumento salarial do que por uma contribuição acerca das possibilidades de aprimoramentos do processo de trabalho.

E aí, eles fazem, assim: dá "A" pra todo mundo, que é mais fácil você dar um feedback de "A", que é aquele negócio que você falou, que é fácil elogiar. E fala assim, no feedback: "olha, eu te avaliei melhor que seus colegas, então, quer dizer, não sou eu que sou o ruim. Quem que te jogou pra baixo foram seus colegas". E aí, vai justificar pro cara porque que não deu o aumento dele. O feedback dele é mais pra justificar porque que não teve aumento do que efetivamente o que que ele precisa melhorar. (Participante do grupo de empregados de carreira técnica)

A colocação de Enriquez (2001) de que um grupo é um espaço em que cada sujeito procura exprimir seus desejos e fazer com que estes sejam considerados importantes pelos outros se encontra inviabilizada, não havendo, portanto, a oportunidade para que o trabalhador possa expressar sua contribuição.

Por outro lado, para além de analisar os percalços do reconhecimento, os trabalhadores tentam se apropriar do modelo, enquanto sua realidade de trabalho, analisam-no e propõem soluções que entendem ser mais apropriadas para o contexto da organização.

Nesse movimento de reflexão e de busca de soluções mais apropriadas para o contexto em questão, faz-se muito presente, nas falas do grupo de gerentes, a necessidade da escuta específica do grupo de empregados dessa instituição. Esse discurso aproxima a concepção de gestão de uma ideia relacional e customizada para um determinado contexto social. Os gerentes que fazem tentativas relacionadas a essa concepção sentem os efeitos positivos produzidos no grupo de empregados.

Eu estou aprendendo um pouco isso. Acho que não é algo que se tira de livro, não é algo que se aprende em curso, é algo que se vivencia na prática. Exige da gente muito ouvir o outro, e eu acho que quando a gente tem uma postura de tentar ser mais justa, normalmente a gente acerta mais (gerente).

A criação de um espaço de escuta e participação dos trabalhadores mostra-se relacionada ao de reconhecimento, sendo demandada pelos empregados de carreira técnica e apontada como solução no discurso gerencial. Tal perspectiva corrobora a ideia de Hegel de que o reconhecimento está associado ao olhar e à validação do outro, presentes nas demandas de fala, nomeação e formalização da pesquisa apresentada. Diante disso, o saber dos gerentes e empregados, presente nas soluções sugeridas, aponta para a construção de uma gestão diferente 
que, sem deixar de se preocupar com o aspecto financeiro, não se restringe a esse, reconhecendo e dando lugar à contribuição fundamental dos trabalhadores.

\section{A inserção do agente comunitário de saúde na estratégia de matriciamento em saúde mental como restauração do reconhecimento e redução do adoecimento destes profissionais}

Veremos, a seguir, uma segunda experiência que, apesar de não ter tido como objetivo trabalhar a questão do reconhecimento, trata também de uma pesquisa-ação, em que ficou clara a questão do adoecimento em profissionais (Agentes Comunitários de Saúde), pela sua não inserção na gestão e pelo não reconhecimento de suas atividades pelos gestores.

Durante os anos de 2015 e 2016 foi realizada, no município de Betim, uma pesquisa-ação que tinha como objetivo compreender a atuação dos Agentes Comunitários de Saúde (ACS), na estratégia de matriciamento em saúde mental. Tal pesquisa buscava, ainda, identificar estratégias pedagógicas que fortalecessem a formação interdiscisciplinar dos atores envolvidos na rede de atenção psicossocial, entre elas, a metodologia de oficinas associada ao estudo de caso. Delineou-se, então, um estudo quantitativo e qualitativo, envolvendo os ACS do SUS Betim. Em sua fase quantitativa, foram aplicados questionários em 338 agentes. O questionário se constituía de três blocos temáticos: dados sociodemográficos; trajetória/atuação como profissional; e concepção de saúde mental. Na etapa seguinte, foram realizadas oito oficinas de educação permanente, como estratégia de intervenção educativa e como instrumento de coletas de dados, em quatro Unidades Básicas de Saúde (UBS). Tal pesquisa revelou, para além das dificuldades em relação ao tratamento dos usuários (encaminhamento, conhecimento da rede), um sofrimento psíquico dos profissionais, em relação à sua não inserção na estratégia de matriciamento em saúde mental.

É importante ressaltar que o matriciamento em saúde mental, de acordo com a Coordenação Geral de Saúde Mental, no documento apresentado à Conferência Regional de Reforma dos Serviços de Saúde Mental em 2003, se constitui em:

um arranjo organizacional que visa outorgar suporte técnico em áreas específicas para equipes responsáveis pelo desenvolvimento de ações básicas de saúde para a população. Nesse arranjo, a equipe por ele responsável compartilha alguns casos com as equipes de saúde local (no caso as equipes da atenção básica responsáveis pelas famílias de um dado território). Esse compartilhamento se produz em forma de coresponsabilização pelos casos, que podem se efetivar através de discussões conjuntas de casos, intervenções conjuntas junto às famílias e comunidades ou em atendimentos conjuntos. (BRASIL, 2003. p. 4).

Esse arranjo organizacional, de acordo com Chiaverini e outros, citados por Fagundes e Deusdedit-Júnior (2016, p.40), "é uma forma de trazer as ações para um nível horizontal, ou seja, a responsabilidade pelos casos não será dirigida somente a determinada função". Ainda de acordo com os autores, o matriciamento oferecerá suporte aos profissionais, para haver essa mudança nas ações. Essa horizontalização decorrente do processo de matriciamento se reestruturará 
em dois tipos de equipes: a equipe de referência, constituída pelos profissionais da UBS ou ESF, de diversas especialidades, e a outra, a equipe de apoio matricial, constituída por profissionais matriciadores em saúde mental na atenção primária, sendo eles: psiquiatras, psicólogos, terapeutas ocupacionais, fonoaudiólogos, assistentes sociais e enfermeiros da saúde mental. Portanto, de acordo com Chiaverini et al (2011),

\begin{abstract}
o processo de saúde-enfermidade-intervenção não é monopólio nem ferramenta exclusiva de nenhuma especialidade, pertencendo a todo o campo da saúde. Isso torna o matriciamento um processo de trabalho interdisciplinar por natureza, com práticas que envolvem intercâmbio e construção do conhecimento. Esse novo modo de produzir saúde situa-se dentro da perspectiva do pensamento construtivista que trabalha com a hipótese de uma eterna reconstrução de pessoas em virtude da interação dos sujeitos com o mundo e dos sujeitos entre si. Essa capacidade se desenvolve no matriciamento pela elaboração reflexiva das experiências feitas dentro de um contexto interdisciplinar em que cada profissional pode contribuir com um diferente olhar, ampliando a compreensão e a capacidade de intervenção das equipes. (CHIAVERINI et al, 2011. p. 16).
\end{abstract}

Para Chiaverini e outros (2011), isso significa atender ao portador de transtornos mentais, em consonância com os princípios do SUS. Segundo eles, um atendimento integral é uma forma de desestigmatizar o louco, que muitas vezes, ao buscar uma unidade básica de saúde, é imediatamente encaminhado a psicólogos e psiquiatras.

Contudo, na prática, nos serviços investigados em Betim, o que observamos é que ainda existe uma verticalização, em relação ao trabalho dos agentes comunitários, pois há um dilema ético entre os profissionais das equipes: como discutir casos da comunidade com profissionais que, apesar de possuírem um conhecimento que pode contribuir no atendimento dos casos, são, ao mesmo tempo, também moradores de tal comunidade? Para resolver tal dilema, as equipes de saúde optam por excluir os agentes comunitários das discussões de casos. Essa exclusão é percebida pelos agentes como fonte de adoecimento.

Em todas as oficinas realizadas, eram proporcionados momentos de escuta desses profissionais e algumas falas chamavam-nos a atenção, nesse sentido.

Nós temos muito desejo de ajudar a comunidade, mas não temos o mesmo conhecimento dos médicos e dos outros profissionais e, por isso, não nos escutam, não nos deixam participar das reuniões e isso também nos adoece. (ACS 1)

Como posso cuidar dos usuários se eu também estou adoecida? Esse trabalho também tem me adoecido, porque sinto que posso ajudar, mas sou impedida. É frustrante quando você sente que pode ajudar e não é escutada. Só escutam quando convém pra eles. (ACS 2)

A segunda fala evidencia o que podemos compreender em Clot (2010) como uma amputação do poder de agir: "uma incapacidade para se exprimir, fazer, relatar e se avaliar" (CLOT, 2010, p.116), o que é adoecedor. Para compreendermos esse adoecimento, convém resgatarmos as contribuições deste mesmo autor, ao assinalar que o trabalho é a atividade que cumpre uma função psicológica. Isso porque, ao "sair de si", o sujeito se vê obrigado a sair de suas préocupações e sobre-ocupar-se de atividades para outrem, sendo isso uma atividade forçada, pois é vinda do exterior. Dessa forma, "As obrigações' contemporâneas são bastante diferentes, mas 
não escapam a esta lei de reciprocidade que o trabalho impõe a cada um: poder "contribuir" por meio dos serviços particulares para a existência de todos, a fim de assegurar a sua própria". (CLOT, 2006, p. 75)

É essa função psicológica que faz com que o sujeito sinta-se útil à sociedade, e estar privado dela é tido como fonte de sofrimento e potencial adoecimento. O que observamos nos casos dos ACS é que essa privação se dá pela estratégia de exclusão de sua participação no processo. Durante a pesquisa, no momento em que foram incluídas e reconhecidas em seu saber, por meio das oficinas realizadas, verificamos que houve uma mudança na forma de esses profissionais perceberem seu papel nos serviços.

Fato é que a pesquisa realizada revelou que a inserção dos ACS nessa nova forma de gestão pode contribuir não só para a melhoria dos serviços, mas também para o não adoecimento desses profissionais. Durante a realização das oficinas, algumas falas apontaram para essa direção:

\begin{abstract}
É muito bom saber que temos um conhecimento que não precisa ser igual do médico, mas que pode ajudar o usuário. Me senti valorizada com essas oficinas, pude perceber que faço muita coisa, que meu trabalho é importante sim. (ACS 3)

Todas as vezes que eu sabia que teria oficina eu vinha trabalhar mais animada, eu comecei a falar sem medo de errar dos casos e vocês valorizaram, quando relatei aquele caso que acompanhei até o CERSAM, eu pude perceber que eu fiz até mais que o médico, foi importante eu ter acompanhado. Meu trabalho é até mais importante que eu pensava. (ACS 4)
\end{abstract}

Em 2017, o CEREST (Centro de Referência em Saúde do Trabalhador) do município de Betim, ao tomar conhecimento da pesquisa, pediu que os proponentes apresentassem os resultados ao serviço, já que o mesmo estava recebendo muitos agentes comunitários queixando-se de sofrimento psíquico relacionado ao trabalho. A partir daí, o CEREST compreendeu a importância de inserir tais profissionais na gestão de trabalho e decidiu incluí-los também na estratégia de matriciamento em saúde do trabalhador.

Essa inserção é necessária, pois, como vimos em Clot, o trabalho proporciona o sentimento de "utilidade social" ao homem, dando-Ihe "fundamento".

\title{
Considerações finais
}

O presente artigo trouxe o relato de duas experiências de pesquisa, realizadas em diferentes contextos do setor público, sendo a primeira na administração indireta e a segunda na administração direta, ambas marcadas pela adoção do modelo de gestão característico do capitalismo financeiro, o qual tem como premissa, entre outras, a submissão e o não reconhecimento do saber dos trabalhadores.

As discussões feitas por meio das duas experiências de pesquisa nos levam a refletir sobre as formas homogêneas de gestão nos setores públicos, bem como revelam que as manifesta- 
ções de sofrimento nas situações de trabalho têm sua origem no que estamos chamando de não reconhecimento desses trabalhadores, por parte dos gestores.

Além de promover uma reflexão crítica sobre a gestão baseada na racionalidade instrumental e que se mostra hegemônica, na atualidade, o presente trabalho, por meio da escuta dos sujeitos trabalhadores, aponta para a possibilidade de construção de uma nova gestão, capaz de promover saúde, satisfação e reconhecimento no trabalho.

É possível que a saída esteja em adotar perspectivas de escuta e participação dos trabaIhadores, como as oficinas nas UBS ou as entrevistas coletivas na empresa do setor de serviços, que aumentem o poder de ação daqueles que trabalham, permitindo que o trabalho seja retirado do estatuto de exploração e adoecimento, para se tornar um mecanismo capaz de promover a saúde e de aprimorar os serviços oferecidos.

Essa premissa de escuta e de valorização do saber dos trabalhadores está em consonância com as teorias das diferentes clínicas do trabalho, como a psicossociologia e a clínica da atividade, que foram utilizadas como referências para as experiências relatadas. Desse modo, o presente artigo também contribui para reforçar a perspectiva crítica dessas clínicas, cujos estudos apontam para a gestão atual como mecanismo de adoecimento físico e mental e propõem a possibilidade de construção de novas formas de gestão que, a partir da participação dos trabalhadores, tornem o trabalho promotor de reconhecimento e capaz de dar um lugar social àqueles que o executam.

As pesquisas relatadas mostram ainda a possibilidade de aplicação das premissas teóricas dessas clínicas em contextos reais de trabalho, demonstrando que a contribuição das mesmas não está restrita ao âmbito acadêmico, podendo ser utilizada para promover melhorias e ganhos, no cotidiano dos trabalhadores e das organizações.

Cabe ressaltar ainda que o presente artigo abre caminho para futuros estudos que permitam comparar a aplicação da perspectiva das clínicas do trabalho em diferentes contextos, bem como desenvolver outras possibilidades de construção coletiva de gestão e formas de trabalho.

\section{Referências}

AMADO, G.; ENRIQUEZ, E. Psicodinâmica do Trabalho e Psicossociologia. In: BENDASSOLLI, P. F.; SOBOLL, L. A. P. Clínicas do Trabalho: Novas Perspectivas para Compreensão do Trabalho na Atualidade. p. 99-109. São Paulo: Atlas, 2011.

ARAÚJO, J. N. G. Trabalho e Temporalidade. Cadernos de Psicanálise - Sociedade de Psicanálise da Cidade do Rio de Janeiro, v.26, n.29, p.35-69. 2010.

BENDASSOLLI, P. F. \& SOBOLL, L. A. P. Clínicas do trabalho: filiações, premissas e desafios. Cadernos de Psicologia Social do Trabalho, vol.14, n.1, pp.59-72, 2011. 
BOLTANSKI, L; CHIAPELLO, E. O novo espírito do capitalismo. São Paulo: Martins Fontes, 2009.

BRASIL. Ministério da Saúde. Saúde mental e atenção básica: o vínculo e o diálogo necessários na inclusão das ações de saúde mental na atenção básica, 2003. Disponível em: $<$ https://www.nescon.medicina.ufmg.br/biblioteca/imagem/1734.pdf>. Acesso em: 10/12/2017.

CHANLAT, J. F. O desafio social da gestão: a contribuição das ciências sociais. In: BENDASSOLLI, P.; SOBOLL, L. A. P. (2011) Clínicas do trabalho - Novas perspectivas para a compreensão do trabalho na atualidade. São Paulo: Editora Atlas, p. 110-131. 2011.

CHIAVERINI, D.H. (org); GONÇALVES, Daniel Almeida; BALLESTER, Dinarte; TÒFOLI, Luis Fernando; CHAZAN, Luiz Fernando; Almeida; FORTES, Sandra. Guia prático de matriciamento em Saúde Mental. Brasília: Ministério da Saúde, Centro de Estudos e Pesquisa em Saúde Coletiva, 2011.

CLOT, Yves. A função psicológica do trabalho. Tradução de Adail Sobral. Petrópolis, RJ: Vozes,2006.

CLOT, Yves. Trabalho e poder de agir. Tradução de Guilherme João de Freitas Teixeira e Marlene Machado Zica Vianna. - Belo Horizonte. Fabrefactum, 2010.

DESPRAIRIES, F., G.; LÉVY, A. Análise de Discurso. In: ENRIQUEZ, E.; Lévy, A.; MICHEL, J. B. Dicionário de Psicossociologia. Lisboa: Climepsi Editora, p. 232-241. 2005.

ENRIQUEZ, E. O vínculo grupal. In: ARAÚJO, J. N. A.; CASTRO, E. M.; MACHADO, M. N. M.; ROEDEL, S. Psicossociologia: Análise social e intervenção. Belo Horizonte: Autêntica, p. 61-74. 2001.

FAGUNDES, E.C. DEUSDEDIT-JÚNIOR, M. Pretextos - Revista da Graduação em Psicologia da PUC Minas v. 1, n. 2, jul./dez. 2016.

GAULEJAC, V. Gestão com doença social. São Paulo: Ideias \& Letras, 2007.

HEGEL, G. W. F. Fenomenologia do espírito. Vol. I e II. 2.ed. Trad. Paulo Meneses. Petrópolis: Vozes, 1992.

LHUILIER, D. Trabalho. In: ENRIQUEZ, E.; LÉVY, A.; MICHEL, J. B. Dicionário de Psicossociologia. Lisboa: Climepsi, p. 210-219. 2005.

PAGÈS, M. et.al. O poder das organizações. São Paulo: Editora Atlas, 1993.

SIQUEIRA, M.V.S. Gestão, violência e servidão nas organizações: Contribuições da sociologia clínica e da psicodinâmica do trabalho. In: MENDES, A. M.; MERLO, A. R.C.; MORRONE, C. F.; FACAS, E. P. (2010) Psicodinâmica e Clínica do Trabalho - Temas, interfaces e casos brasileiros. Curitiba: Juruá, 2010. 